\title{
Antimicrobial Efficacy of Titanium Dioxide Coating in Operating Theaters at A Tertiary Care Hospital in Arunachal Pradesh
}

\author{
Mika Umpo ${ }^{1 *}$, Tumbi Lollen², Moji Jini ${ }^{3}$ and Jyothinath Kothapalli ${ }^{4}$ \\ ${ }^{1}$ Department of Microbiology, Tomo Riba Institute of Health and Medical Sciences, \\ Naharlagun - 791 110, Arunachal Pradesh, India. \\ 2Department of Dentistry, Tomo Riba Institute of Health and Medical Sciences, \\ Naharlagun- 791 110, Arunachal Pradesh, India. \\ ${ }^{3}$ Department of Surgery, Tomo Riba Institute of Health and Medical Sciences, \\ Naharlagun-791110, Arunachal Pradesh, India. \\ ${ }^{4}$ Department of Anatomy, Tomo Riba Institute of Health and Medical Sciences, \\ Naharlagun- 791 110, Arunachal Pradesh, India.
}

\begin{abstract}
SmartCoat is a novel technology with titanium dioxide $\left(\mathrm{TiO}_{2}\right)$ nanoparticles, isopropyl alcohol, and distilled water as the active ingredients. $\mathrm{TiO}_{2}$, along with water and oxygen, generates highly reactive $\mathrm{OH}$ radicals that can neutralize bacteria and other microorganisms and remove volatile organic compounds (VOCs). Smart coat requires air circulation and a light source for its catalytic activity. The efficacy of $\mathrm{TiO}_{2}$ in industrial setups and dental devices has been documented. The present study aimed to evaluate the efficacy of TiO2 in preventing microbial growth in an operating theater (OT) where maximum sterility is desired to prevent sepsis and nosocomial infections. Among the four operating theaters, two were selected. Periodic swab samples taken over a period of nine months from OT 3 (Smart coated) and OT 4 (Control) showed minimal variations in terms of microbial growth in the processed swabs. The findings were statistically analyzed using a paired-sample t-test. The computed value of ' $t$ ' i.e., 2.084 was lower than the critical value of 3.18 at 3 deg of freedom (df) and hence was not significant. The null hypothesis cannot be rejected $(p=0.129>0.05)$ at the $5 \%$ level of significance. SmartCoat with $\mathrm{TiO}_{2}$ was not effective in preventing microbial growth on biomedical devices in the OT. The product may not be suitable for operating theaters unless it is supplemented by other sterilization procedures. However, it can be used in other healthcare settings and in public places.

Keywords: SmartCoat, titanium dioxide, nanoparticles, relative light units, operation theatre, nosocomial infections, sepsis
\end{abstract}

*Correspondence: athupopu@gmail.com; +91 7005783916

(Received: July 30, 2021; accepted: October 04, 2021)

Citation: Umpo M, Lollen T, Jini M, Kothapalli J. Antimicrobial Efficacy of Titanium Dioxide Coating in Operating Theaters at A Tertiary Care Hospital in Arunachal Pradesh. J Pure Appl Microbiol. 2021;15(4):2177-2182. doi: 10.22207/JPAM.15.4.41

(C) The Author(s) 2021. Open Access. This article is distributed under the terms of the Creative Commons Attribution 4.0 International License which permits unrestricted use, sharing, distribution, and reproduction in any medium, provided you give appropriate credit to the original author(s) and the source, provide a link to the Creative Commons license, and indicate if changes were made. 


\section{INTRODUCTION}

Titanium dioxide $\left(\mathrm{TiO}_{2}\right)$ is a considerably effective nano-semiconductor photocatalyst that is commonly utilized in organic and inorganic compound oxidation in water and air because of its extended photostability and vigorous oxidative potential. $\mathrm{TiO}_{2}$ is a cheap and innocuous material ${ }^{1}$ that produces extremely reactive $\mathrm{OH}$ radicals in the presence of $\mathrm{O}_{2}$ and $\mathrm{H}_{2} \mathrm{O}$. These $\mathrm{OH}$ radicals can effectively prevent bacterial growth and development. ${ }^{2}$

Infections associated to bacteria pose a considerable threat to the well-being of patients in the healthcare system. Infections with Staphylococcus aureus is the leading cause of patient morbidity. Several reports have indicated the existence of methicillin-resistant Staphylococcus aureus on hospital surfaces for up to 5 months. During non-lethal UV light exposure, $\mathrm{TiO}_{2}$ nanoparticles degrade organic compounds by continuous discharge and the emergence of superoxide ions and hydroxyl radicals, which restrict the growth of methicillin-resistant Staphylococcus aureus. ${ }^{3}$

SmartCoat is a new-generation technology with the following active ingredients: $\mathrm{TiO}_{2}$, nanoparticles, isopropyl alcohol, and distilled water. SmartCoat India Pvt. Ltd claims that it has antibacterial, antiviral, and antifungal properties and removes volatile organic compounds (VOCs). It is a deodorizing agent, and it acts as a self-cleaning agent. $\mathrm{TiO}_{2}$ has a nano size of $2-3 \mathrm{~nm}$ for the greatest coverage to reacts with any light source to eradicate $99.9 \%$ of fungi, bacteria, viruses, and VOCs. According to the SmartCoat India Pvt. Ltd, 1000 relative light units (RLU) are recommended microbial levels as per the Lumitester document. The supply of light (measured in RLU) and air circulation is necessary for the functioning of this coating, as it is developed on photocatalyst technology.

There is a lack of literature on the efficacy of SmartCoat in microbial prevention in the primitive zones of health care. Various approaches with different compositions of surface coats have yet to be explained. The present study aimed to evaluate the advantage of $\mathrm{TiO}_{2}$ coated surfaces in preventing substantial microbial growth in the OT of TRIHMS Hospital, where the maximum sterility procedure is adopted.

\section{MATERIALS AND METHODS}

This cross-sectional observational study was carried out in the Department of Microbiology, Tomo Riba Institute of Health \& Medical Sciences (TRIHMS), a 300 bed state hospital located in the capital complex of Naharlagun, Arunachal Pradesh, from June to December 2020. Among the four operating theaters (OTs) at TRIHMS, two OTs were selected for the study. To avoid any bias, two OTs (OT 3 and OT 4) were selected randomly. The study proposal was approved by the institutional research committee and the institutional ethics committee.

\section{Sampling and cultivation}

One swab was taken from the OT table, bedside monitor, anesthesia machine, and operating microscope before application of $\mathrm{TiO}_{2}$ (SmartCoat). Darcon-tipped sterile swabs hydrated with sterile water were swabbed on the surface to be tested. The test swab was then inserted in the tube, shaken to integrate in the water at the bottom of the swab tube. The swab tube was then tested using the Kikkoman Lumitester PD 20, and the results were recorded.

Thereafter, Germisep tablets were mixed in water ( 1 tablet in 10 L water). Germisep dissolves chlorine in water. This solution was then sprayed on the interiors of OT 3 with an electrostatic sprayer (ESS). The ESS sprays electrically charged molecules to the liquid to increase its spread and adherence over the surface .

\section{SmartCoat and its application}

The photo catalyst SmartCoat product is a liquid containing $\mathrm{TiO}_{2}$ nanoparticles as the main ingredient, along with isopropyl alcohol and distilled water. Regardless of the surface to which it is applied, SmartCoat technology neutralizes any organic matter upon contact via its oxidative ability, which is triggered utilizing any available light.

SmartCoat was applied to the walls, floor, roof, tables, surgical items, and all equipment inside OT 3 by an ESS and supplied sufficient light and air. This was left to dry for $30 \mathrm{~min}$ with all lights switched on, in OT 3. After $30 \mathrm{~min}$, swabs were taken from the same three sites.

The collected swabs were taken to the Department of Microbiology laboratory and were inoculated on Sabouraud dextrose agar (SDA) and nutrient agar. Readings of culture media were 
Umpo et al. | J Pure Appl Microbiol | 15(4):2177-2182 | December 2021 | https://doi.org/10.22207/JPAM.15.4.41

Table 1. Culture reports showing growth of various microbial floras at periodical interval

\begin{tabular}{|c|c|c|}
\hline Time period & Operation theatre 3 & Operation theatre 4 \\
\hline End of $1^{\text {st }}$ week & Bacillus Species & $\begin{array}{c}\text { Candida species } \\
\text { Coagulase negative staphylococcus }\end{array}$ \\
\hline End of $2^{\text {nd }}$ week & $\begin{array}{c}\text { Staphylococcus species } \\
\text { Proteus Mirabilis } \\
\text { Micrococcus species }\end{array}$ & $\begin{array}{c}\text { Staphylococcus species } \\
\text { Bacillus Species }\end{array}$ \\
\hline End of 1 month & $\begin{array}{l}\text { Bacillus Species } \\
\text { Alcaligenes species }\end{array}$ & $\begin{array}{c}\text { Staphylococcus Aureus } \\
\text { Bacillus Species }\end{array}$ \\
\hline End of 2 month & $\begin{array}{l}\text { Moraxella Species } \\
\text { Alcaligenes species }\end{array}$ & $\begin{array}{l}\text { Staphylococcus Aureus } \\
\text { Moraxella Species }\end{array}$ \\
\hline End of $3^{\text {rd }}$ month & Moraxella Species & $\begin{array}{l}\text { Staphylococcus Aureus } \\
\text { Moraxella Species }\end{array}$ \\
\hline End of $6^{\text {th }}$ month & Moraxella Species & Staphylococcus Aureus \\
\hline End of $9^{\text {th }}$ month & Moraxella Species & Staphylococcus Aureus \\
\hline
\end{tabular}

Table 2. Prevalence of microbial growth in operation theatre 3 and 4

\begin{tabular}{lccccc}
\hline $\begin{array}{l}\text { Bacterial/Fungal } \\
\text { grown }\end{array}$ & \multicolumn{2}{c}{$\begin{array}{c}\text { Operation theatre } 3 \\
\text { Number of } \\
\text { cultures }\end{array}$} & $\begin{array}{c}\text { Percentage } \\
\text { of growth }\end{array}$ & $\begin{array}{c}\text { Number of } \\
\text { cultures }\end{array}$ & $\begin{array}{c}\text { Percentage } \\
\text { of growth }\end{array}$ \\
\hline Moraxella & 1 & $11.1 \%$ & 2 & $14.2 \%$ \\
Bacillus Species & 2 & $22.2 \%$ & 2 & $14.2 \%$ \\
Staphylococcus & 1 & $11.1 \%$ & & 6 & $42.8 \%$ \\
Micrococcus & 2 & $22.2 \%$ & 1 & $7.14 \%$ \\
Proteus & 1 & $11.1 \%$ & 0 & $0 \%$ \\
Alcaligenes & 2 & $22.2 \%$ & 0 & $0 \%$ \\
Candida Species & 0 & $0 \%$ & 1 & $7.14 \%$ \\
CoNS & 0 & $0 \%$ & 1 & $7.14 \%$ \\
Aspergillus & 0 & $0 \%$ & 1 & $7.14 \%$ \\
\hline
\end{tabular}

performed and recorded after $24 \mathrm{~h}$ of incubation at $37^{\circ} \mathrm{C}$. Growth was recorded, and biochemical tests were performed to identify the isolates.

Thereafter, periodic swabs were collected and cultured to identify the microbial flora. Periodical swabs were collected at the end of $1^{\text {st }}$ week, $3^{\text {rd }}$ week, $1^{\text {st }}$ month, $2^{\text {nd }}$ month, $3^{\text {rd }}$ month, $6^{\text {th }}$ month and $9^{\text {th }}$ month after applying SmartCoat.

\section{Statistical Analysis}

Statistical analysis was performed using SPSS version 16.0. Frequencies and percentages (\%) were calculated. Significant differences in antimicrobial effects were assessed using Student's t-test. Statistical significance was set at $\mathrm{p}<0.05$.

\section{RESULTS}

Periodic culture isolates from both OT 3 (with SmartCoat) and OT 4 (without SmartCoat) showed minimal variation. Staphylococcus (42.2\%), Moraxella (14.2\%), and Bacillus species $(14.2 \%)$ were mostly isolated from the surface of OT 4. However, Bacillus species (22.2\%), Micrococcus (22.2\%), and Alcaligenes (22.2\%) were most commonly observed on the OT 3 surface coated with SmartCoat. At nine months OT 3 (with SmartCoat) showed low RLU, and only Moraxella species were grown in one of the cultures. However, in OT 4, Staphylococcus, Moraxella, and fungi were observed.

The computed value of ' $t$ ', i.e., 2.084 is lower than the critical value of 3.18 at 3 degrees of freedom (df) and hence it is not significant. Therefore, the null hypothesis cannot be rejected $(p=0.129>0.05)$ at the $5 \%$ level of significance.

\section{DISCUSSION}

Titanium dioxide is a heterogeneous 
Table 3. Significance of differences in outcome of the antimicrobial effects

\begin{tabular}{|c|c|c|c|c|c|c|c|}
\hline & \multicolumn{4}{|c|}{ Paired Differences } & \multirow[t]{3}{*}{$\mathrm{t}$} & \multirow[t]{3}{*}{$\mathrm{df}$} & \multirow[t]{3}{*}{ Sig.(2-tailed) } \\
\hline & \multirow[t]{2}{*}{ Mean $\pm S D$} & \multirow{2}{*}{$\begin{array}{l}\text { Std. Error } \\
\text { Mean }\end{array}$} & \multicolumn{2}{|c|}{ 95\% $\mathrm{Cl}$ difference } & & & \\
\hline & & & Lower & Upper & & & \\
\hline $\begin{array}{l}\text { Pair } 1 \text { After- } \\
\text { After } 9 \text { months }\end{array}$ & $2.122 \pm 2036.197$ & 1018.098 & -1118.29 & 5361.793 & 2.084 & 3 & 0.129 \\
\hline
\end{tabular}

catalyst and is becoming a preferred choice as an antimicrobial coating for dental implants, orthopedic devices, and other health care facilities to prevent microbial growth. Several combinations have been reported; unfortunately, none of these methods have scientific reliability and integration. The present cross-sectional observational study was designed to evaluate the efficacy of $\mathrm{TiO}_{2}$ in preventing microbial growth in OTs. A wide range of studies have reported that photocatalysis is harmful to many organisms, including viruses, Gram +Ve / -Ve bacteria, algae, fungi, and protozoa, and is also effective in inactivating prions. ${ }^{4} \mathrm{TiO}_{2}$ can kill Gram +Ve and Gram -Ve bacteria in water, air, and on surfaces of various materials. ${ }^{5} \mathrm{TiO}_{2}$ photocatalysis is an economically feasible approach that uses water and hydrogen peroxide to fabricate an active $\mathrm{TiO}_{2}$ surface on titanium substrates. Under UV illumination, the organic substance is degraded by producing reactive oxygen species. ${ }^{6}$

The amalgamation of the $\mathrm{Ag}$ matrix and $\mathrm{TiO}_{2}$ nanoparticles enhances the antibacterial effect by promoting $\mathrm{Ag}$ ion release and increasing
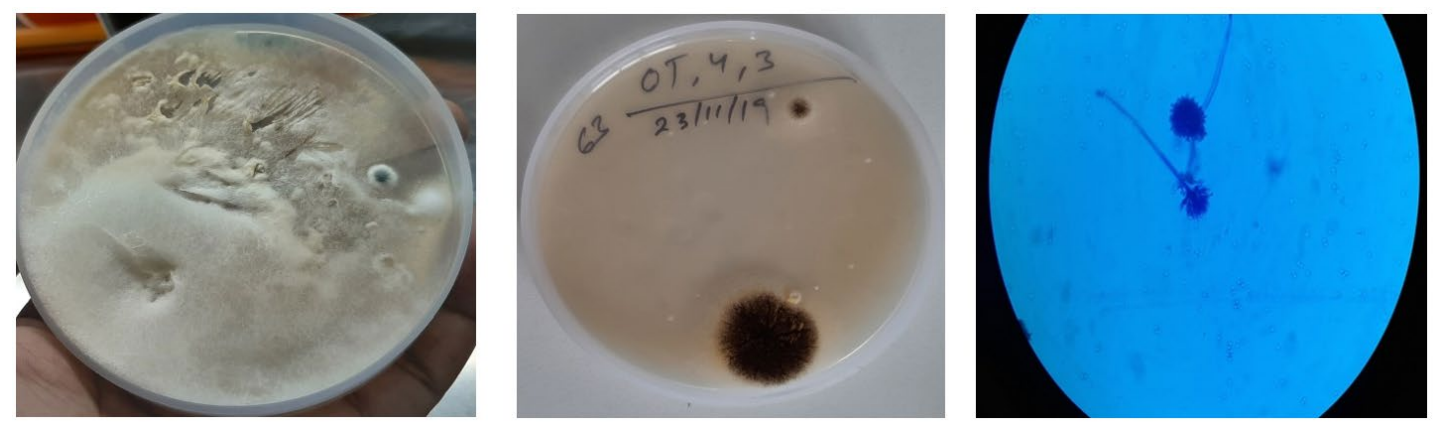

Fig. 1. Culture and stained image representing the growth of Aspergillus Niger.

A. Initial white colonies, B. While colonies changed to black after few days producing conidial spores. The edges of colonies appear pale yellow producing radial fissures. C. Staining image representing Aspergillus Niger.

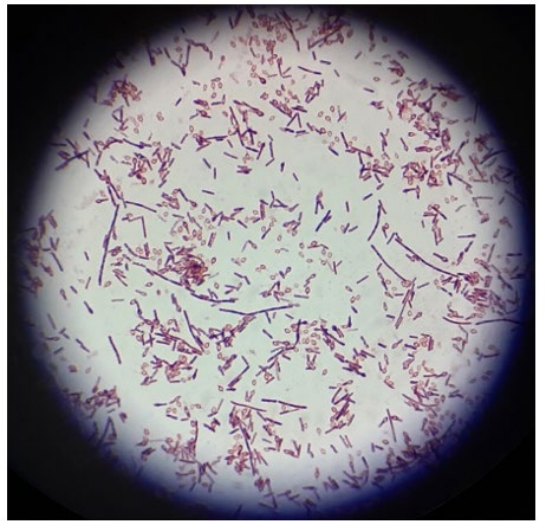

Fig. 2. Gram stain of culture isolates shows mixed growth with most bacillus species. the negative surface charge of the coatings. ${ }^{7}$ A study by Unosson stated that $\mathrm{Ag}-\mathrm{TiO}_{2}$ can increase the photocatalytic properties, and incorporation of $\mathrm{Ag}$ into titanium biomaterials have effective antibacterial strategies. ${ }^{6}$ Visai et al. stated that photocatalytic sterilizing surfaces act in the absence of chemical material and electricity; instead, they require oxygen, light, and water. The surfaces of $\mathrm{TiO}_{2}$ are nontoxic and do not impact the environment negatively. This makes $\mathrm{TiO}_{2}$ substances a preferable option for the establishment of a health care setup. ${ }^{8}$

$\mathrm{TiO}_{2}$ surfaces have two important characteristic features, self-cleaning and self-disinfection, which act against bacteria. 
Degradation of organic substances by total oxidation prevents bacterial and biofilm adhesion on the surface of biomedical devices. ${ }^{9}$ Sunanda et al. stated that irradiated $\mathrm{TiO}_{2}$ surfaces kill bacteria in a three-step mechanism, such as cell wall invasion by reactive oxygen species, decomposition of the inner cytoplasmic membrane, and decomposition of toxic bacterial components.

In this study, the photo catalyst SmartCoat product is a liquid containing $\mathrm{TiO}_{2}$ nanoparticles as the main ingredient, and isopropyl alcohol and distilled water, were sprayed on biomedical devices in OT 3. Periodic culture isolates from both OT 3 (with SmartCoat) and OT 4 (without SmartCoat) showed minimal variation. Bacillus species $(22.2 \%)$, Micrococcus $(22.2 \%)$, and Alcaligenes (22.2\%) were the most common isolated species on the OT 3 surface coated with SmartCoat. However, in OT 4, Staphylococcus (42.2\%), Moraxella (14.2\%), and Bacillus species (14.2\%) were commonly isolated. Nine months after application of the SmartCoat product, OT 3 (with SmartCoat) showed low RLU and only Moraxella species was present. However, in OT 4, Staphylococcus, Moraxella, and fungi were observed.

Chun et al. tested steel orthodontic wires coated with $\mathrm{TiO}_{2}$, which remained unchanged after adhesion tests, whereas uncoated wires increased their mass by $4.97 \% .{ }^{10} \mathrm{~A}$ study by Chow Wai Leng et al. stated that samples from untreated surfaces with $\mathrm{TiO} 2$ and ad hoc samples were more likely to be culture positive (Methicillin-Resistant Staphylococcus aureus (9.2\%) and gram negative bacteria (1.4\%) and $\mathrm{TiO}_{2}$ did not influence positive culture results. ${ }^{11}$

\section{CONCLUSION}

Application of SmartCoat in OT 3 resulted in low RLU and growth of Moraxella species in the cultures. SmartCoat, a $\mathrm{TiO}_{2}$-based product, may not prevent microbial growth on biomedical devices in the OTs and may not be suitable for OTs unless it is supplemented by other OT sterilization procedures. The OT requires a maximum sterile environment to prevent sepsis and nosocomial infections. However, SmartCoat can be used in other healthcare facilities to minimize or prevent nosocomial infections.

\section{ACKNOWLEDGMENTS}

We are indebted to the all faculties of Department of Anaesthesiology for their constant support.

\section{CONFLICT OF INTEREST}

conflict of interest.

The authors declare that there is no

\section{AUTHORS' CONTRIBUTION}

MU, MJ conceptualized the study. MU, TL did the data acquisition. MU, JK, MJ, TL performed data analysis and interpretated the results, wrote the manuscript and did the revision. All authors read and approved the final version of the manuscript.

\section{FUNDING}

None.

\section{DATA AVAILABILITY}

All datasets generated or analyzed during this study are included in the manuscript

\section{ETHICS STATEMENT}

The Study is approved by the Institutional Ethics Committee of Tomo Riba Institute of Health and Medical Sciences.

\section{REFERENCES}

1. Binas V, Venieri D, Kotzias D, Kiriakidis G. Modified $\mathrm{TiO}_{2}$ based photo catalysts for improved air and health quality. J Materionics. 2017;3(1):3-16. doi: 10.1016/j. jmat.2016.11.002

2. Rodrigues-Silva C, Miranda SM, Lopes FVS, et al. Bacteria and Fungi inactivation by photocatalysis under UVA irradiation: Liquid \& gas phase. Environ Sci Pollut Res. 2017;24(7):6372-6381. doi: 10.1007/s11356-0167137-8

3. Shah MSA, Nag M, Kalagara T, Singh S, Manorama SV. Silver on PEG-PU-TiO ${ }_{2}$ polymer nano Composite films; an excellent system for antibacterial applications. Chem materials. 2008;20(7):2455-2460. doi: 10.1021/ cm7033867

4. Paspaltsis I, Kotta K, Lagoudaki R, Grigoriadis N, Poulios I, Sklaviadis T. Titanium dioxide photocatalytic inactivation of prions. J Gen Virol. 2006;87(10):31253130. doi: 10.1099/vir.0.81746-0

5. Foster HA, Ditta IB, Varghese S, Steele A. Photocatalytic disinfection using titanium dioxide: spectrum and mechanism of antimicrobial activity. Appl Microbiol Biotechnol. 2011;90(6):1847-1868. doi: 10.1007/ s00253-011-3213-7

6. Unosson E. Antibacterial Strategies for Titanium Biomaterials. Digital Comprehensive Summaries of 
Uppsala Dissertations from the Faculty of Science and Technology 1250. 2015:72. Uppsala: Acta Universitatis Upsaliensis. ISBN 978-91-554-9241-0.

7. Liu C, Geng L, Yu Y, et al. Reduction of bacterial adhesion on Ag-TiO2 coatings. Materials Letters. 2018;218:334-336. doi: 10.1016/j.matlet.2018.02.044

8. Visai L, De Nardo L, Punta C, et al. Titanium oxide antibacterial surfaces in biomedical devices. Int $\mathrm{J}$ Artif Organs. 2011;34(9):929-946. doi: 10.5301/ ijao.5000050

9. Carp O, Huisman CL, Reller A. Photoinduced reactivity of titanium dioxide. Prog Solid State
Chem. 2004;32(1-2):33- 177. doi: 10.1016/j. progsolidstchem.2004.08.001

10. Sunada K, Watanabe T, Hashimoto K. Studies on photokilling of bacteria on $\mathrm{TiO}_{2}$ thin film. J Photochem Photobiol A: Chemistry. 2003;156(1-3):227-233. doi: 10.1016/S1010-6030(02)00434- 3

11. Leng CW, Soe TA, Wui LW, et al. Efficacy of titanium dioxide compounds in preventing environmental contamination by meticillin resistant Staphylococcus aureus (MRSA). Int J Infect Control. 2013;9(3):1-8. doi: 10.3396/IJIC.v9i3.022.13 